\title{
Insights into the concept of fish welfare
}

\author{
Gilson Luiz Volpato ${ }^{1, *}$, Eliane Gonçalves-de-Freitas ${ }^{2}$, \\ Marisa Fernandes-de-Castilho ${ }^{3}$
}

\begin{abstract}
${ }^{1}$ Research Center on Animal Welfare (CNPq), Laboratory of Animal Physiology and Behavior, Department of Physiology, Instituto de Biociências, Caunesp, Universidade Estadual Paulista, Cx Postal 510, 18618-000 Botucatu, São Paulo, Brazil

${ }^{2}$ Research Center on Animal Welfare (CNPq), Laboratory of Animal Behavior, Department of Zoology and Botany, Instituto de Biociências, Letras e Ciências Exatas, Caunesp, Universidade Estadual Paulista, CEP 15054-000, São José do Rio Preto, São Paulo, Brazil

${ }^{3}$ Research Center on Animal Welfare (CNPq), Laboratory of Studies on Animal Stress, Department of Physiology, Section of Biological Sciences, Universidade Federal do Paraná, Cx Postal 1903, CEP 81531-970, Curitiba, Paraná, Brazil
\end{abstract}

\begin{abstract}
Fish welfare issues are predicated on understanding whether fish are sentient beings. Therefore, we analyzed the logic of the methodologies used for studying this attribute. We conclude that empirical science is unable to prove or to disprove that fish are sentient beings. Thus, we propose a combined ethical-scientific approach for considering fish as sentient beings. The most difficult ongoing question is to determine which conditions fish prefer. Approaches to assess fish preferences should be rigorously and cautiously employed. In light of these considerations, attempts to establish physiological standards for fish welfare are discouraged, and a preference-based definition of fish welfare is proposed.
\end{abstract}

KEY WORDS: Welfare $\cdot$ Pain $\cdot$ Stress $\cdot$ Aquaculture $\cdot$ Consciousness $\cdot$ Sentience $\cdot$ Preference $\cdot$ Fish Resale or republication not permitted without written consent of the publisher

\section{INTRODUCTION}

Aquaculture is a growing human initiative supported by complex industrial technologies. Massive quantities of fish are produced each year for food, sport, home aquaria (ornamentation), or restocking programs. These practices may impinge on fish welfare through capture methods, high stocking densities, and transport of fish. Moreover, catch-and-release practices impose additional discomfort or even pain for fish. Scientific research also creates stress for fish, and thus, authors are increasingly requested by journal editors to receive approval of the experimental protocol from ethics committees to ensure that fish do not suffer excessively.

The emergence of concerns for satisfactory conditions for fish has also stimulated interest in theoretical and philosophical problems such as whether fish are, in fact, sentient creatures. Concomitant to these academic discussions, guidelines for the proper treatment of fish have been developed (FSBI 2002, Johansen et al. 2006); however, a clear concept of fish welfare and a methodological means to assess this internal state are still controversial.

Numerous reviews have extensively detailed the work performed in fish welfare (Fraser 1993, Lehman 1998, Salzen 1998, Balon 2000, Broom 2001, Désiré et al. 2002, Rose 2002, Rushen 2003, Chandroo et al. 2004, Conte 2004, Sandoe et al. 2004, Hastein et al. 2005, Dawkins 2006a,b, Duncan 2006, Huntingford et al. 2006, Veissier \& Boissy 2006). Therefore, this review will focus mainly on the direction of future research on this issue. To begin, we describe the most difficult, but most important, problem of determining whether fish are emotionally conscious (sentient) of suffering and discomfort. Next, studies aiming to identify an empirical basis for consciousness in fish are described. Scientific methodology is unable to assess this problem in fish and other non-human animals, and validation of concerns for fish welfare should be tempered by ethical considerations. Then, we analyze the main approaches for the conceptualization of fish welfare and discuss preference tests in fish. The use of fish conditions as a means to interpret fish welfare is discussed. 
In conclusion, we present a preference-based definition of fish welfare.

\section{ATTRIBUTES NECESSARY TO JUSTIFY CON- CERNS ABOUT FISH WELFARE}

In order to consider the welfare of an organism, it must be conscious of at least some basic emotion. Thus, fish welfare should only be of concern if fish are not only aware but also conscious. That is, the fish must have the ability to subjectively experience pain, coldness, comfort, discomfort, and to consciously differentiate perceived internal states as 'good or bad', 'pleasant or unpleasant', etc. Such an ability, termed sentience, is a necessary attribute for concerns about animal welfare (Dawkins 2006b, Duncan 2006, Huntingford et al. 2006). Based upon this definition, pain is a conscious experience, while nociception is an unconscious response to noxious stimuli.

Although subjective, perception of suffering has been applied to fish in order to support considerations of fish welfare (Huntingford et al. 2006). According to Spinelli (1987), suffering is a very unpleasant emotional condition that results from physical pain, emotional pain, and/or intolerable discomfort. However, some degree of discomfort (something less than suffering) may also exist. For instance, an environment without refuge, or with limited stimulation, could be uncomfortable (but not suffering) for a fish.

\section{INVESTIGATION OF SENTIENCE IN FISH AND OTHER NON-HUMAN ANIMALS}

\section{Approaches to investigate sentience}

Sentience has been studied using 3, not entirely independent, approaches. One approach involves identifying brain machinery in non-human animals that is homologous to that involved in human consciousness. This method is based on the Darwinian evolutionary theory that predicts that similar structures beget similar functions and that if the same function occurs, similar structures exist. For instance, fish forebrain areas were compared to the mammalian amygdala and hippocampus, which are areas associated with memory, learning, and emotions. Recently, numerous investigators have employed this approach in fish (Dietrich et al. 2002, Rodriguez et al. 2002a,b, Sneddon 2002, 2003a,b, Chandroo et al. 2004, Portavella et al. 2004, Dunlop \& Laming 2005, Hoglund et al. 2005). Along these same lines, a more sophisticated technique involves the treatment of fish with a noxious stimulus followed by utilization of molecular tech- niques to visualize activity in the fish brain. Subsequently, the active brain regions can be evaluated for homology to regions stimulated in mammals by similar noxious stimuli (Braithwaite \& Boulcott 2007, this issue).

A second approach to the study of sentience in fish is aimed at corroborating pain by investigating the physiological mechanisms expected to underlie sentience. Sneddon et al. $(2003 a, b)$ showed that A-delta and $\mathrm{C}$ fibers in the trout Oncorhynchus mykiss trigeminal nerve contain the same 2 types of nociceptors that occur in humans. Despite these observations, the presence of the necessary machinery does not necessarily indicate that fish feel pain. In order to determine whether these homologous nociceptors are functional, the trout nociceptor system was blocked by administration of a painkiller (morphine) to the fish following exposure to the noxious stimuli. Acetic acid and bee venom were chosen as stimuli because they induce irritation and inflammation in mammals. In this experiment, trout responded by behaving normally after morphine administration (Sneddon 2003b). This association of a painkiller with the disappearance of painlinked behaviors demonstrated that fish are indeed affected by nociceptive stimuli. Similar studies involving physiological measurement have also been conducted (Jansen \& Green 1970, Ehrensing et al. 1982, Chervova 1997, Porteros et al. 1999).

A third approach to determining sentience in fish examines behavioral changes following exposure to noxious stimuli. In this method, no physiological or pharmacological intervention is used. These studies are of 2 types: (1) correlation between well-accepted pain or fear stimuli and behavioral changes; (2) evaluation of complex cognitive abilities, such as spatial learning (Odling-Smee \& Braithwaite 2003) and stressinduced changes in memory (Moreira \& Volpato 2004, Moreira et al. 2004, Barreto et al. 2006).

\section{Logic of the empirical basis of sentience in fish}

Dawkins (1997) analyzed the difficulty in studying welfare in non-human beings and argued that the subject is within the realm of science and that the main difficulty is methodological. Thus, the scientific approaches are valid, but more time is necessary to obtain valid results. We argue, however, that the study of mental states in non-human animals is beyond the scope of empirical science, and thus, ethical concerns are necessary.

Considering the 3 approaches described in the previous section, we present the following argument: (1) human beings have emotions (our own experience; Salzen 1998); (2) human emotions are generated by 
specific brain structures (Servan-Schreiber \& Perlstein 1998); (3) similar brain structures in different animals generate similar functions (e.g. emotions); (4) some non-human animals have brain structures homologous to human brain structures (Chandroo et al. 2004 for fish); (5) therefore, we conclude that non-human animals that have human-like brain structures have human-like emotions.

The logical weakness of this argument is that premise 3 is necessary but lacks empirical support, since emotions cannot be quantified in non-human animals (Sandoe et al. 2004). In fact, the same or a very similar function may inevitably emerge from 2 similar but not identical structures. By presuming premise 3, the following syllogism should be accepted: (1) in human beings, brain structure $B$ generates emotions; (2) non-human animals have brain structure $B_{i}$ (3) therefore, brain structure B generates emotions in nonhuman animals. This argument is valid if, and only if, brain structure B is exactly the same for both human and non-human animals. Because these animals are only similar to each other, from a strictly logical point of view, this argument is not valid.

In this debate, a consequent argument is that science can neither prove nor disprove that fish are sentient organisms. Thus, empirical science is unable to offer a definitive answer. Sandoe et al. (2004) argue that this lack of proof is the inevitable condition of empirical science and that the addition of corroborating evidence will not change this conundrum. This condition has become a point of emphasis in texts on the welfare of non-human animals (Rushen 2003, Sandoe et al. 2004, Hastein et al. 2005, Dawkins 2006b, Duncan 2006).

A precautionary ethical position assumes that, in the absence of convincing contrary evidence, fish are sentient. This position is based upon the following premises: (1) science is unable to offer a definitive answer to the fish-sentience problem; (2) common sense suggests that sentient beings should be treated well; (3) therefore, following a precautionary approach, fish should be treated well. Therefore, if we must handle these organisms (e.g. to produce food for humans), we should assume that they might suffer. This argument implies that sport fishing should be abolished and that capture fishing and fish farming should be conducted in a manner that results in minimal discomfort for the fish.

\section{THE CONCEPT OF FISH WELFARE}

\section{Internal state of welfare}

Welfare is an internal state in which the animal 'feels well'; thus, references to 'poor' or 'low' welfare are meaningless and should be phrased as the 'absence of welfare'. Attention has focused on avoiding or minimizing suffering in animals; however, pleasure has not been considered (Duncan 2006, Veissier \& Boissy 2006). Identification of the internal state of welfare is still a challenge. A sick fish is certainly not in a state of welfare (Dawkins 2006a), but a healthy fish may not necessarily be feeling well.

Following the success of physiological characterization of stress in animals, attempts to physiologically define fish welfare were encouraged. This attempt is clearly not feasible. Stress is the reaction of the fish to challenges (stressors) that necessarily demand its energy. Thus, the stress response involves the release of catecholamines and corticosteroids into the blood, and these products mobilize stored energy and stimulate emergency pathways to energetically enable the animal to cope with the stressor (see Barton 2002). This physiological pattern stems from the need to provide sufficient energy and environmental information to cope with the perceived challenge. Thus, stress is clearly a mechanism shaped by evolution. For the internal state of welfare, however, such a standard physiological response is not expected. Instead, a wide range of physiological responses occur because life is not at risk. For instance, apparently pleasurable activities (sex and hunting prey) cause physiological patterns similar to those of seemingly unpleasant conditions (e.g. escaping from a predator) (Rushen 1991).

\section{The productivity approach}

The productivity approach (Fraser 1993) assumes that productivity measures (e.g. growth rate and reproduction) are reliable indicators of fish welfare. In contrast, a study carried out in Volpato's laboratory indicate that Nile tilapia Oreochromis niloticus juveniles chose to remain in an environment illuminated by yellow light although these fish developed better in an environment illuminated by blue light as measured by feeding, food conversion rate, growth, and survival. Further studies corroborated that the blue environment decreased physiological stress (Volpato \& Barreto 2001) and facilitated reproduction (Volpato et al. 2004) in this species. For other animal species, Fraser (1993) points out that some practices increase productivity but harm the animal. These conditions include increased stocking densities, use of antibiotics to avoid diseases in sub-optimal environments, and strong genetic selection for certain productivity traits (which may weaken other biological traits; see also Grandin \& Deesing 1998). Petit et al. (2003) found that the largemouth bass 
Micropterus salmoides reared in continuous light grew faster than those reared with the natural light cycle; however, growth in continuous light conditions likely threatens fish welfare. The welfare state of a fish should be considered solely in terms of its biological performance, as economic and biological performance are not necessarily compatible (Luescher et al. 1989). These examples indicate that productivity measures (e.g. biomass produced) may not match welfare requirements.

\section{ASSESSING FISH WELFARE}

Since the internal welfare state of an organism cannot be defined in physiological terms, preference (choice) tests may be the only means to determine the welfare of fish (see Dawkins 2006b). This methodology is referred to as the 'fish-preference approach'.

Fish are undoubtedly capable of making decisions. The spotted catfish Pseudoplatystoma coruscans, a voracious carnivorous species, can decide whether to attack or to retreat from a conspecific fish using chemical cues for assessment of conspecific size (Giaquinto \& Volpato 2005). This decision may be crucial for survival as a small conspecific fish is prey while a larger conspecific fish is a voracious predator. Decision making in fish may involve cognitive processes (see Braithwaite \& Boulcott 2007) or merely innate mechanisms for recognizing other fish and displaying the specific response (Kelley et al. 1999, Jordão \& Volpato 2000).

For the assessment of fish welfare, accepting the fish-preference approach is reasonable based on the assumption that a sentient creature (this possibility is the background for examining fish welfare conditions) does not freely choose a condition of discomfort when presented with better conditions. In practical terms, these fish-preferences provide useful information about the preferred conditions of individual space, light intensity and color, feeding time, daily feeding quantities, shading needs, water column depth, water flow, and many others. Guidelines for holding fish should be directed by these results.

Fraser (1993) reports that while a British government committee recommended that hens in battery cages should not be housed on fine-gauged hexagonal 'chicken wire', Hughes \& Black (1973) found that hens that were allowed to choose from different types of floor preferred the fine wire flooring. Although animals are assumed to choose the best immediate or ultimate condition, methods for identifying these preferences require a cautious approach for fish, as was seen previously for other animals such as farm birds and mammals.

\section{Precautions for implementing the preference test approach}

Provide a wide range of opportunities

When fish preferences are chosen from only a few possibilities, the results reflect preferences from only the opportunities presented and not necessarily the conditions that the fish prefer. Thus, the fish should be presented with several possibilities for any given situation (e.g. temperature, salinity, light color, etc.). For example, temperature preference should ideally be determined from fish exposure to a continuous gradient of temperature. Also, the inclusion of both favorable and unfavorable conditions may provide a contrast reference for preferences. Freedom of choice, however, is imperative in such preference tests.

Avoid bias from the test area

Any conditions (light, wall marks, sound, etc.) that may affect fish choice must be examined before the beginning of a choice test (e.g. mazes test, shelter, position in the tank). To minimize interference of fixed cues from the outside area, the position of the test apparatus inside the area should be presented in different combinations (each combination being different for each individual). Brotto \& Araújo (2001) evaluated the preferences of 5 fish species on the southeast Brazilian coast. Preferences for different forms and complexities of artificial shelters were determined in the natural environment. Deposition of the shelters in the testing area was random to avoid test area interference.

Avoid bias from the apparatus

In order to measure fish spatial preferences, any preferences within the apparatus must be determined before introduction of the test stimuli. For instance, in a Y-maze test, fish are expected to randomly (50\%) select a particular path. If data show otherwise, the apparatus is introducing a preference bias. In addition, a choice in one apparatus does not necessarily imply that this same choice will be made in another condition, such as holding the fish. Thus, successive tests are required to develop a more comprehensive understanding of fish preferences.

\section{Measure of preference}

Common variables for measuring preference include latency to display a choice, time spent in a chosen 
condition, and frequency of choice. Caution must be exercised when comparing these results. Frequency of choice and time spent in a condition may have very different meanings. Moreover, a first choice may be different from subsequent choices (in fish, GomezLaplaza 2005; in chickens, Shields et al. 2004).

\section{Intensity of preference}

In order to determine the importance of a particular choice, Duncan (2006) suggests measuring the strength of the preference. Importance may reflect the effort the animal will expend to obtain its preferred choice (see also Dawkins \& Beardsley 1986, Mason et al. 1998, 2001).

\section{Precautions for interpreting the preference test approach}

Fish biological conditions

Intrinsic factors, such as phylogeny, biological rhythms, ontogeny, ecology, grouping, and individual condition, determine the preference choices made by fish. For example, while grouping is a homeostatic condition for schooling or shoaling species, this lifestyle is stressful for territorial species (Wirtz \& Davenport 1976). Fish also have biological clocks interacting cyclically with environmental changes, such as photoperiod, temperature fluctuations, seasonal changes in climate, lunar phases, tidal movements, rainy periods etc. (Bateson 2004, see review by Volpato \& Trajano 2006). Petit et al. (2003) argue that feeding is generally synchronized by daylight, and thus, feeding at the 'wrong' time may result in lower feed intake. Li \& Dowling (1998) found that the visual sensitivity of the fish Danio rerio is under endogenous circadian control, and thus, time of day may affect their choices. Ontogenetic changes also affect the needs of a fish (Duncan 2006). For example, feeding preferences change during development for many species (Huntingford 1993). Acclimatization to previous ecological (or tank) conditions may affect subsequent choices. In one example, a combination of fixed genetic traits (adaptation) and plastic responses to temperature explained differences in enzyme and mRNA concentrations in fish distributed in environments differing by $15^{\circ} \mathrm{C}$ (Crawford \& Powers 1989). Grouping imposes social rank in territorial species, and this rank determines physiological patterns as a consequence of social stress (Fernandes \& Volpato 1993, Volpato \& Fernandes 1994, Barreto \& Volpato 2006). Social stress is an internal state that affects which shoal a fish joins, with the choice being related to the joining member's familiarity with the fish already in the shoal and its social rank relative to them (e.g. in the angelfish Pterophyllum scalare; Gomez-Laplaza 2005). Chemical recognition of predators (Jordão \& Volpato 2000) or large conspecifics (Giaquinto \& Volpato 2005) affects fish behavior. As a result, fish may react differently to water supplied from different sources depending on the species present in the water supply. Further, individual experience, or other traits, may affect fish preferences. The recent classification of fish as bold or shy (Brown et al. 2005) suggests that fish personality also affects individual preferences. Moreover, the ability of fish to learn by association may induce stress not only from the known stressors but also from unstressful cues (conditioned stimulus) after the fish learn to associate these cues with a stressor (unconditioned stimulus) (Moreira \& Volpato 2004). Other relevant individual traits are strain, sex, costs to get a resource, and time of access in the test, as suggested by Bateson (2004).

\section{Preference or attention?}

In studies of Japanese quail chicks Coturnix japonica, Carmichael et al. (1998) noted that the test stimuli may attract the attention of the animal and introduce bias. Thus, the test preference may be more a perceptual consequence than a free choice. Furthermore, the novelty of the test stimulus may attract the attention of the animal (Darmaillacq et al. 2004). Repeated testing can be used to overcome this problem.

\section{Spatial tendency of the fish}

Functional specialization of the right and left side of the brain has been demonstrated in fish and may affect the preference test. Gambusia holbrooki, Xenotoca eiseni, and Betta splendens have a marked preference for using the right eye when attacking a mirror image or a live rival (Bisazza \& Santi 2003).

\section{Overly hasty inferences}

The key to understanding preferences is to be precise with the analysis. For instance, Mariani \& Alcoverro (1999) studied the preferences of herbivorous fishes for seagrasses in a multi-choice feeding preference test. The results were based on correlations between bite marks on the leaves and total carbon content of these plants. Although these researchers concluded that the fish preferred low-carbon plants, many differences existed between the compared plants, and 
the correlation obtained may not reflect the causal factor that attracted the fish. Thus, each stimulus must be specifically tested.

\section{CONCLUSION}

Since empirical science is unable to objectively determine whether fish are sentient beings, ethical concerns should assume that fish are conscious beings. Thus, these animals may suffer or be in discomfort when not treated well. While utilizing fish physiological patterns for determination of welfare is discouraged, preference tests provide useful information that will improve fish welfare. Importantly, fish welfare is not only freedom from suffering but also access to comfort states. The fish-preference approach, which admittedly requires caution with respect to implementation, overcomes these inherent problems and offers insight for approaches to fish welfare. Accordingly, we propose a definition of the state of fish welfare based on fish preferences: the internal state of a fish when it remains under conditions that were freely chosen.

Acknowledgements. The authors thank T. G. Pottinger for clarification of the term 'welfare', A. Pereira Júnior for criticism, clarification, and suggestions about the philosophical aspects of this review, V. A. Braithwaite for information on fish neural pathways for pain and for kindly allowing us to read the Braithwaite \& Boulcott manuscript published in this issue, and the editor H. I. Browman for helpful suggestions that improved the manuscript.

\section{LITERATURE CITED}

Balon EK (2000) Defending fish against recreational fishing: an old problem to be solved in the new millennium. Environ Biol Fishes 57:1-8

Barreto RE, Volpato GL (2006) Stress responses of the fish Nile tilapia subjected to electroshock and social stressors. Braz J Med Biol Res 39:1605-1612

Barreto RE, Volpato GL, Pottinger TG (2006) The effect of elevated blood cortisol levels on the extinction of a conditioned stress response in rainbow trout. Horm Behav 50: 484-488

Barton BA (2002) Stress in fishes: a diversity of responses with particular reference to changes in circulating corticosteroids. Integr Comp Biol 42:517-525

Bateson M (2004) Mechanisms of decision-making and the interpretation of choice tests. Anim Welf 13(Suppl):S115S120

Bisazza A, Santi de A (2003) Lateralization of aggression in fish. Behav Brain Res 141:131-136

Braithwaite VA, Boulcott P (2007) Pain perception, aversion and fear in fish. Dis Aquat Org 75:131-138

Broom DM (ed) (2001) Coping with challenge. Welfare in animals including humans. Dahlem University Press, Berlin

Brotto DS, Araújo FG (2001) Habitat selection by fish in an artificial reef in Ilha Grande bay, Brazil. Braz Arch Biol Technol 44:319-324
Brown C, Jones F, Braithwaite VA (2005) In situ examination of boldness-shyness traits in the tropical poeciliid, Brachyraphis episcope. Anim Behav 70:1003-1009

Carmichael NL, Jones RB, Mills AD (1998) Social preferences in Japanese quail chicks from lines selected for low or high social reinstatement motivation: effects of number and line identity of the stimulus birds. Appl Anim Behav Sci 58:353-363

Chandroo KP, Duncan IJH, Moccia RD (2004) Can fish suffer? Perspectives on sentience, pain, fear and stress. Appl Anim Behav Sci 86:225-250

Chervova LS (1997) Pain sensitivity and behavior of fishes. J Ichthyol 37:98-102

Conte FS (2004) Stress and the welfare of cultured fish. Appl Anim Behav Sci 86:205-223

Crawford DL, Powers DA (1989) Molecular basis of evolutionary adaptation at the lactate dehydrogenase-B locus in the fish Fundulus heteroclitus. Proc Natl Acad Sci USA 86: 9365-9369

Darmaillacq AS, Chechery R, Poirier R, Dickel L (2004) Effect of early feeding experience on subsequent prey preference by cuttlefish, Sepia officinalis. Dev Psychobiol 45: $239-244$

Dawkins MS (1997) DGM Wood-Gush Memorial lecture: Why has there not been more progress in animal welfare research? Appl Anim Behav Sci 53:59-73

Dawkins MS (2006a) A user's guide to animal welfare science. Trends Ecol Evol 21:77-82

Dawkins MS (2006b) Through animal eyes: What behaviour tells us. Appl Anim Behav Sci 100:4-10

Dawkins MS, Beardsley TM (1986) Reinforcing properties of access to litter in hens. Appl Anim Behav Sci 15:351-364

Désiré L, Boissy A, Veissier I (2002) Emotion in farm animals: a new approach to animal welfare in applied ethology. Behav Proc 60:165-180

Dietrich M, Hofmann MH, Bleckmann H (2002) Effects of dopaminergic drugs and telencephalic ablation on eye movements in the goldfish, Carassius auratus. Brain Res Bull 57:393-395

Duncan IJH (2006) The changing concept of animal sentience. Appl Anim Behav Sci 100:11-19

Dunlop R, Laming P (2005) Mechanoreceptive and nociceptive responses in the central nervous system of goldfish (Carassius auratus) and trout (Oncorhynchus mykiss). J Pain 6:561-568

Ehrensing RH, Michell GF, Kastin AJ (1982) Similar antagonism of morphine analgesia by MIF-1 and naloxone in Carassius auratus. Pharmacol Biochem Behav 17:757-761

Fernandes MO, Volpato GL (1993) Heterogeneous growth in the Nile tilapia: social stress and carbohydrate metabolism. Physiol Behav 54:319-323

Fraser D (1993) Assessing animal well-being: common sense, uncommon science. In: Food animal well-being. Purdue University Office of Agricultural Research Programs, West Lafayette, IN, p 37-54. Available at www.ansc.purdue.edu/ wellbeing/FAWB/1993/Food_Animal_Well_Being.html

FSBI (Fisheries Society of the British Isles) (2002) Fish welfare. Briefing Paper 2. Granta Information Systems, Cambridge

Giaquinto PC, Volpato GL (2005) Chemical cues related to conspecific size in pintado catfish, Pseudoplatystoma coruscans. Acta Ethol 8:65-69

Gómez-Laplaza LM (2005) The influence of social status on shoaling preferences in the freshwater angelfish (Pterophyllum scalare). Behaviour 142:827-844

Grandin T, Deesing MJ (1998) Genetics and animal welfare. In: Grandin $\mathrm{T}$ (ed) Genetics and behaviour of domestic animals. Academic Press, San Diego, CA, p 319-341 
Hastein T, Scarfe AD, Lund VL (2005) Science-based assessment of welfare: aquatic animals. Rev Sci Tech Off Int Epizoot 24:529-547

Hoglund E, Weltzien FA, Schjolden J, Winberg S, Ursin H, Doving KB (2005) Avoidance behavior and brain monoamines in fish. Brain Res 1032:104-110

Hughes BO, Black AJ (1973) The preference of domestic hens for different types of battery cage floor. Br Poul Sci 14: $615-619$

Huntingford FA (1993) Development of behaviour in fish. In: Pitcher TJ (ed) Behaviour of teleost fishes. Chapman \& Hall, London, p 47-68

Huntingford FA, Adams C, Braithwaite VA, Kadri S, Pottinger TG, Sandoe P, Turnbull JF (2006) Current issues in fish welfare. J Fish Biol 68:332-372

Jansen GA, Green NM (1970) Morphine metabolism and morphine tolerance in goldfish. Anesthesiology 32:231-235

Johansen R, Needham JR, Colquhoun DJ, Poppe TT, Smith AJ (2006) Guidelines for health and welfare monitoring of fish used in research. Lab Anim 40:323-340

Jordão LC, Volpato GL (2000) Chemical transfer of warning information in non-injured fish. Behaviour 137:681-690

Kelley JL, Graves JA, Magurran AE (1999) Familiarity breeds contempt in guppies. Nature 401:661-662

Lehman H (1998) Animal awareness. App Anim Behav Sci 57: 315-325

Li L, Dowling JE (1998) Zebrafish visual sensitivity is regulated by a circadian clock. Vis Neurosci 15:851-857

Luescher UA, Friendship RM, Lissemore KD, McKeown DB (1989) Clinial ethology in food animal practice. Appl Anim Behav Sci 22:191-214

Mariani S, Alcoverro T (1999) A multiple-choice feedingpreference experiment utilising seagrasses with a natural population of herbivorous fishes. Mar Ecol Prog Ser 189: 295-299

Mason G, McFarland D, Garner J (1998) A demanding task: using economic techiniques to assess animal priorities. Anim Behav 55:1071-1075

Mason G, Cooper J, Clarebrough C (2001) Frustrations in fur-farmed mink. Nature 410:35-36

Moreira PSA, Volpato GL (2004) Conditioning of stress in Nile tilapia. J Fish Biol 64:961-969

Moreira PSA, Pulman KGT, Pottinger TG (2004) Extinction of a conditioned response in rainbow trout selected for high or low responsiveness to stress. Horm Behav 46:450-457

Odling-Smee L, Braithwaite VA (2003) The influence of habitat stability on landmark use during spatial learning in the 3-spined stickleback. Anim Behav 65:701-707

Petit G, Beauchaud M, Attia J, Buisson B (2003) Food intake and growth of largemouth bass (Micropterus salmoides) held under alternated light/dark cycle (12L:12D) or exposed to continuous light. Aquaculture 228:397-401

Portavella M, Torres B, Salas C, Papini MR (2004) Lesions of the medial pallium, but not of the lateral pallium, disrupt spaced-trial avoidance learning in goldfish (Carassius auratus). Neurosci Lett 362:75-78

Porteros A, Garcia-Isidoro M, Barrallo A, González-Sarmiento R, Rodriguez RE (1999) Expression of ZFORDI, $\delta$-opioid receptor, in the central nervous system of the zebrafish (Danio rerio). J Comp Neurol 412:429-438

Rodríguez F, López JC, Vargas JP, Broglio C, Gómez Y, Salas
C (2002a) Spatial memory and hippocampal pallium through vertebrate evolution: insights from reptiles and teleost fish. Brain Res Bull 57:499-503

Rodríguez F, López JC, Vargas JP, Gómez Y, Broglio C, Salas C (2002b) Conservation of spatial memory function in the pallial forebrain of reptiles and ray-finned fishes. J Neurosci 22:2894-2903

Rose JD (2002) The neurobehavioral nature of fishes and the question of awareness and pain. Rev Fish Sci 10:1-38

Rushen J (1991) Problems associated with the interpretation of physiological data in the assessment of animal welfare. Appl Anim Behav Sci 28:381-386

Rushen J (2003) Changing concepts of farm animal welfare: bridging the gap between applied and basic research. Appl Anim Behav Sci 81:199-214

Salzen EA (1998) Emotion and self-awareness. Appl Anim Behav Sci 57:299-313

Sandoe P, Forkman B, Christiansen SB (2004) Scientific uncertainty - how should it be handled in relation to scientific advice regarding animal welfare issues? Anim Welf 13(Suppl):S121-S126

Servan-Schreiber D, Perlstein WM (1998) Limbic activation and its relevance to emotional disorders. Cogn Emot 12: 331-352

Shields SJ, Garner JP, Mench JA (2004) Dustbathing by broiler chickens: a comparison of preference for four different substrates. Appl Anim Behav Sci 87:69-82

Sneddon LU (2002) Anatomical and electrophysiological analysis of the trigeminal nerve in a teleost fish, Oncorhynchus mykiss. Neurosci Lett 319:167-171

Sneddon LU (2003a) Trigeminal somatosensory innervation of the head of a teleost fish with particular reference to nociception. Brain Res 972:44-52

Sneddon LU (2003b) The evidence for pain in fish: the use of morphine as an analgesic. Appl Anim Behav Sci 83:153-162

Sneddon LU, Braithwaite VA, Gentle MJ (2003a) Do fish have nociceptors? Evidence for the evolution of a vertebrate sensory system. Proc R Soc Lond B 270:1115-1121

Sneddon LU, Braithwaite VA, Gentle MJ (2003b) Novel object test: examining pain and fear in the rainbow trout. J Pain $4: 431-440$

Spinelli JS (1987) Reducing pain in laboratory animals. Lab Anim Sci Special Issue:65-70

Veissier I, Boissy A (2006) Stress and welfare: two complementary concepts that are intrinsically related to the animal's point of view. Physiol Behav (in press) doi: 10.1016/j.physbeh.2006.11.008

Volpato GL, Barreto RE (2001) Environmental blue light prevents stress in the fish Nile tilapia. Braz J Med Biol Res 34:1041-1045

Volpato GL, Fernandes MO (1994) Social control of growth in fish. Braz J Med Biol Res 27:797-810

Volpato GL, Trajano E (2006) Biological rhythms. In: Val LA, Val VMFA, Randal DJ (Org) Fish physiology. Elsevier, San Diego, CA, p 101-153

Volpato GL, Duarte CRA, Luchiari AC (2004) Environmental color affects Nile tilapia reproduction. Braz J Med Biol Res 37:479-483

Wirtz P, Davenport J (1976) Increased oxygen consumption in blennies (Blennius pholis L.) exposed to their mirror images. J Fish Biol 9:67-74

Submitted: July 9, 2006; Accepted: February 20, 2007

Proofs received from author(s): March 20, 2007 